\title{
Torakoabdominale aortaaneurismer - åpen kirurgi og endovaskulær behandling
}

\author{
Sammendrag \\ Bakgrunn. Torakoabdominale aorta- \\ aneurismer affiserer aorta descendens \\ og ulike deler av abdominalaorta. Her \\ gir vi en oversikt over denne type aneu- \\ rismer og prognose, utredning og \\ behandlingsmuligheter.
}

\begin{abstract}
Materiale og metode. Artikkelen er basert på egne kliniske erfaringer og en ikke-systematisk gjennomgang av relevant litteratur.
\end{abstract}

Resultater. 30-dagersmortaliteten etter elektive operasjoner er i dag $4-15 \%$ avhengig av aneurismets utbredelse, den underliggende sykdom og tilstedeværelse av symptomer. Forekomsten av nevrologisk sekvele som paraplegi og paraparese rapporteres hos 2-10\%. Endovaskulære teknikker og ulike kombinasjoner med åpen kirurgi er blitt tatt i bruk de siste årene. I tillegg brukes nå ofte ekstrakorporal sirkulasjon, perfusjon av nyreog mesenterialkar, sekvensiell avklemming av aorta og proteksjon av ryggmargen.

Fortolkning. Resultatene etter operasjon for torakoabdominalt aortaaneurisme er blitt stadig bedre. Inngrepene forutsetter et multidisiplinært samarbeid mellom kirurg, anestesilege og radiolog. En grundig preoperativ utredning er essensielt. Alle muligheter for terapi låpen kirurgi, stentgrafting og hybridoperasjoner) bør være tilgjengelig.
Hans Olav Myhre

hans.myhre@ntnu.no

Kirurgisk klinikk

Asbjørn Ødegård

Klinikk for bildediagnostikk

St. Olavs hospital

Olav Kyrres gate 17

7006 Trondheim

Anders Winnerkvist

Roar Stenseth

Klinikk for hjerte- og lungekirurgi

St. Olavs hospital

Hjerteklinikken St. Elisabeth

Hans Nissens gate 3

7018 Trondheim

Et torakoabdominalt aortaaneurisme affiserer aorta descendens og ulike deler av abdominalaorta inklusive viscerale avgangskar. Det er mange utfordringer knyttet til behandlingen av denne aneurismeformen. Fryktede komplikasjoner er paraplegi, paraparese, multiorgansvikt og affeksjon av nyre-, hjerte- og lungefunksjon. Nyere metoder for organproteksjon har medvirket til å redusere denne risikoen (1).

Moderne behandling av torakoabdominale aortaaneurismer ble innført av Crawford (2). Ostiene til nyrearterier, a. coeliaca og a. mesenterica superior og litt av det omliggende aortavev blir anastomosert til åpninger i en aortaprotese som ekskluderer aneurismet fra sirkulasjonen. Også interkostalarterier kan reanastomoseres på denne måten. I begynnelsen ble det brukt direkte avklemming av aorta uten distal perfusjon. Metoden er tidligere omtalt i Tidsskriftet (3). I løpet av de siste 20 år har det skjedd flere tekniske fremskritt, blant annet med distal perfusjon av aorta og ulike metoder for beskyttelse av ryggmarg og indre organer (4-7). Dessuten er endovaskulære metoder og kombinasjonsinngrep også blitt tatt i bruk (8-11). I denne artikkelen gjennomgår vi de ulike typene torakoabdominale aortaaneurismer og prognose, utredning og behandlingsmuligheter.

\section{Materiale og metode}

Denne oversiktsartikkelen er bygd på forfatternes kliniske erfaringer og en ikke-systematisk gjennomgang av relevant litteratur.

\section{Klassifikasjon og prognose}

Insidensen av torakoabdominale aortaaneurismer er ukjent, men det er påvist en økende forekomst av torakale så vel som infrarenale abdominale aortaaneurismer. Noe av forklaringen er økningen i antall eldre i befolkningen.
Torakoabdominale aortaaneurismer kan ha ulik etiologi. Tradisjonelt har man ansett at aneurismene oppstår på aterosklerotisk basis og at dette oftest skyldes aldersbetingede degenerative forandringer $i$ tunica media. Tilstanden forekommer også som en komplikasjon til type B-aortadisseksjon, Marfans syndrom, arteritter som Takayasus sykdom eller infeksjon.

Utbredelsen av torakoabdominale aortaaneurismer klassifiseres etter Crawford og medarbeidere (12), og klassifikasjonen er modifisert av andre (13) (fig 1). Disse aneurismene omfatter også ostiene til a. coeliaca, a. mesenterica superior og nyrearteriene. Klassifisering er viktig for å definere utstrekningen av sykdomsprosessen og er nyttig når man skal planlegge behandlingen.

Naturalforløpet av torakoabdominale aortaaneurismer er studert av Crawford \& DeNatale (14). Etter to år var bare $24 \%$ av pasientene i live, og halvparten av dødsfallene skyldtes ruptur. I Crawfords operasjonsmateriale var derimot femårsoverlevelsen $59 \%$. Selv om gruppene ikke er helt sammenliknbare, er dette likevel en antydning av gevinsten ved operasjon. Som de fleste aneurismer er de torakoabdominale ofte symptomfrie inntil det kommer smerter på grunn av ekspansjon eller ruptur. Smertene kan være lokalisert til abdomen, bryst eller rygg, avhengig av aneurismets utstrekning og eventuelt ruptursted. De fleste aneurismer oppdages tilfeldig, for eksempel ved CT-undersøkelse for andre symptomer i bryst eller mage.

\section{Operasjonsindikasjoner og preoperativ utredning}

Åpen kirurgi ved torakoabdominalt aortaaneurisme er et stort inngrep. Omtrent halv-

\section{Hovedbudskap}

- Behandlingsresultatene ved torakoabdominale aortaaneurismer er blitt bedre de siste årene

- Flere pasienter kan tilbys kirurgisk behandling

- Behandlingen er ressurskrevende og forutsetter et godt multidisiplinært samarbeid

- Samtlige behandlingsmetoder - åpen kirurgi, hybridoperasjoner og stentgrafting - bør være tilgjengelig 


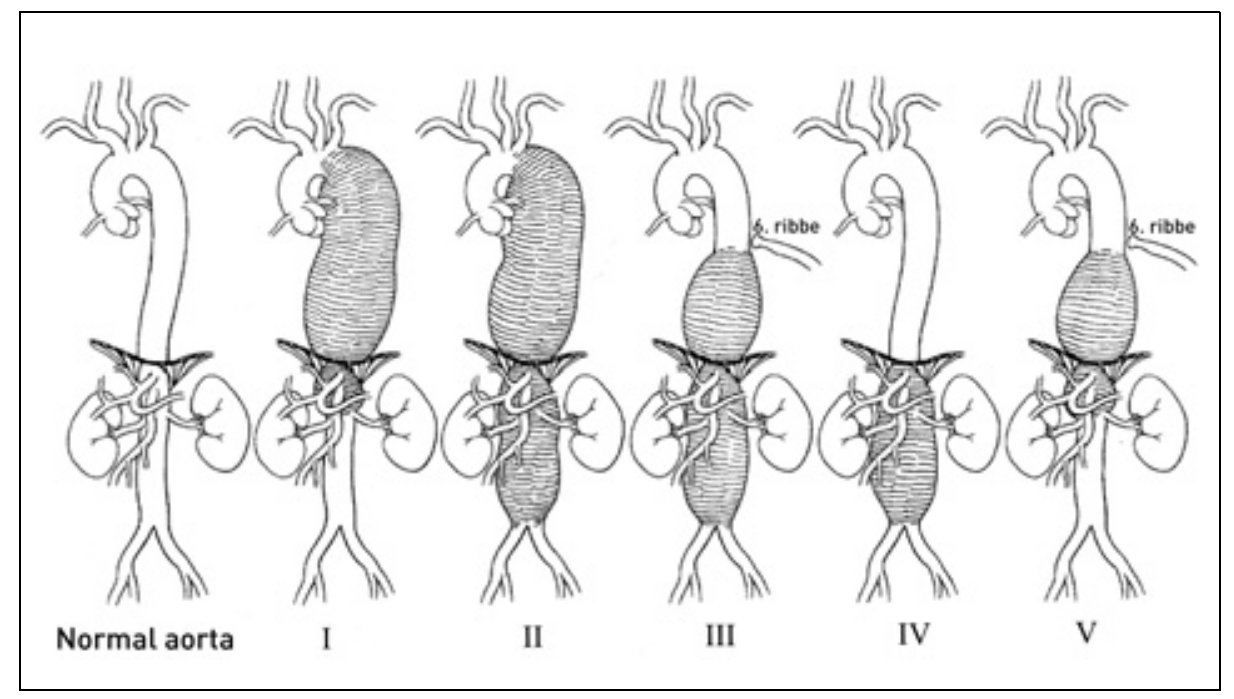

Figur 1 Crawfords inndeling av torakoabdominale aortaaneurismer, modifisert av Safi. Type I starter like etter venstre a. subclavia og inkluderer hele aorta descendens og øvre del av abdominalaorta, vanligvis til nyrearteriene. Type II-aneurismer går ut fra samme nivå som type I-aneurismene, men affiserer hele abdominalaorta. Type III-aneurismer affiserer distale del av aorta descendens og hele abdominalaorta. Type IV-aneurismer involverer hele abdominalaorta fra diafragma til aortabifurkaturen. Type V-aneurismer affiserer aorta fra 6. interkostalrom til over nyrearteriene. Gjengitt med tillatelse fra Hazim J. Safi (13)

parten av pasientene har koronar hjertesykdom, og mange har kronisk obstruktiv lungesykdom. Hos pasienter som har nedsatt nyrefunksjon på forhånd er det risiko for postoperativ nyresvikt. En preoperativ ut-

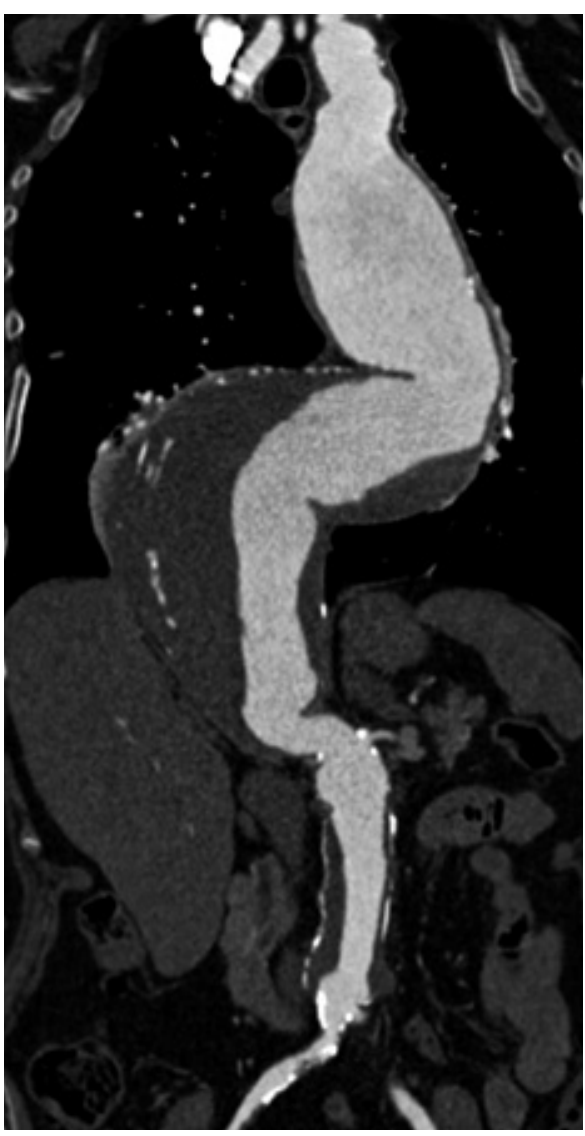

Figur 2 CT-undersøkelse med kontrast som fremstiller et torakoabdominalt aortaaneurisme. Denne pasienten hadde tidligere fått innsatt en rørprotese i den infrarenale del av abdominalaorta på grunn av aneurisme redning innebærer derfor en omfattende undersøkelse, særlig av hjerte- og lungefunksjonen. Ekkokardiografi gjøres blant annet for å vurdere aortaklaffens funksjon. Koronar angiografi gjøres rutinemessig mange steder. Ved positive funn går man videre med angioplastikk eller koronar bypass før aortaoperasjonen.

Som hovedregel er det indikasjon for operasjon hvis aneurismets maksimale diameter er $6 \mathrm{~cm}$ eller mer. Alder, leveutsikter, allmenntilstand, eventuell bindevevssykdom og organfunksjon har også betydning for fastsettelse av operasjonsindikasjon. Eksempelvis er det sjelden at man opererer meget gamle pasienter for et type II-aneurisme, mens risikoen ved operasjon for et type IV-aneurisme er lavere (15). I de tilfellene hvor det foreligger symptomer eller tegn på manifest ruptur, vil det uansett være en relativt sterk indikasjon for operasjon, med mindre man regner sjansen for at pasienten skal overleve inngrepet som liten (16).

Den viktigste bildediagnostiske metoden ved torakoabdominalt aortaaneurisme er CT-undersøkelse med kontrast (fig 2). Både torakal- og abdominalaorta samt bekkenkar bør fremstilles. Ved alvorlig nyresvikt kan MR-undersøkelse uten kontrast være en alternativ bildediagnostisk metode.

\section{Det operative inngrepet}

Profylaktisk antibiotika gis før operasjonen og i to dager. Pasienten intuberes med dobbeltlumentube. Venstre lunge kollaberes slik at tilgangen til torakalaorta bedres og manipulering av lungen reduseres. Det kan være betydelig blødning under inngrepet, og det er nødvendig med flere gode intravenøse tilganger. Det innbefatter bl.a. et grovkalibret 2-lumen sentralt venekateter koblet til utstyr

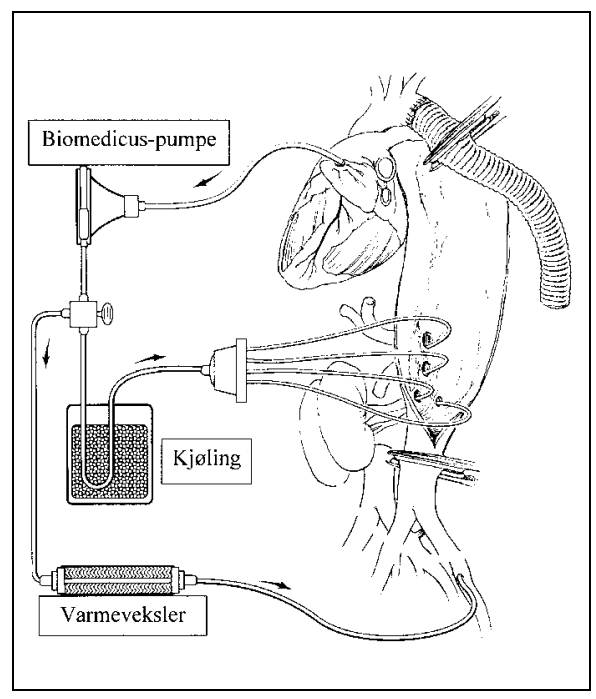

Figur 3 Skjematisk fremstilling av partiell ekstrakorporal sirkulasjon med sideløp for å perfundere nyrearteriene og de viscerale kar. $\emptyset$ Øre anastomose på torakalaorta er sydd ferdig. Gjengitt med tillatelse fra Hazim J. Safi (13)

som tillater infusjon av opptil $500 \mathrm{ml} / \mathrm{min}$ fra et reservoar som er fylt med blodprodukter etter behov. Samtidig benyttes to blodvaskemaskiner for å ta vare på mest mulig av pasientens eget blod. For blodtrykks- og sirkulasjonskontroll legges arteriekatetre inn i høyre a. radialis og femoralis samt et lungearteriekateter. Et intratekalt kateter legges inn mellom L3 og L4 for måling av spinalvæsketrykk. Spinalvæske dreneres slik at man holder trykket under $10 \mathrm{~mm} \mathrm{Hg}$. Dette kateteret ligger til tredje postoperative dag (17).

Pasienten ligger på operasjonsbordet i skrått høyre sideleie. Det gjøres en torakoabdominal incisjon fra like proksimalt for symfysen på skrå mot venstre over kostalbuen og vanligvis inn i 5. interkostalrom. Ved type IV-aneurismer legges den torakale del av incisjonen noe lavere, eller man kan enkelte ganger nøye seg med laparotomi. De viscerale organer som milt, venstre nyre og tarm mobiliseres over mot høyre og den aneurismatiske aorta er dermed tilgjengelig. Heparin (100 IE/kg) gis før kanylering. Det anlegges partiell kardiopulmonal bypass, vanligvis fra en lungevene, ved bruk av sentrifugalpumpe (Biomedicus) og varmeveksler. Blodet føres tilbake til pasienten via a. femoralis i lysken. Det tilstrebes et distalt arterietrykk på minst $60 \mathrm{~mm} \mathrm{Hg}$, noe avhengig av pasientens preoperative trykk (18). I denne fasen av operasjonen perfunderes kroppens proksimale deler fra hjertet mens distale deler forsynes fra sentrifugalpumpen (fig 3). Det kan, spesielt under større pågående blødning, være en utfordring å balansere to parallelle kretsløp.

Disseksjonen begynner proksimalt, og hvis mulig klemmer man aorta av sekvensielt slik at det blir en trinnvis utsjalting av de ulike aortasegmenter. Slik kan man opprett- 
holde perfusjon til nyrer, tarm og interkostalarterier mens man utfører den øvre anastomosen ende til ende til aorta. Den utvidede aorta erstattes av en syntetisk blodåreprotese av polyester. Etter at øvre anastomose er ferdig, fortsetter man rekonstruksjonen i distal retning og implanterer interkostalarterier i T8-T12-nivået. Dette gjøres vanligvis via et sidehull i hovedprotesen $(1,5-7)$. Deretter klemmes abdominalaorta av og man perfunderer a. coeliaca, a. mesenterica superior og begge nyrearteriene med blod via et såkalt blekksprutkateter (octopus) fra arterieslangen i den ekstrakorporale krets. Nyrene kjøles separat for å oppnå en beskyttende effekt. I tillegg til å opprettholde tilstrekkelig blodføring til nyrene er det viktig å måle perfusjonstrykket $(5,7)$.

Hvis aneurismet ikke er for stort, kan a. coeliaca, a. mesenterica superior og høyre nyrearterie anastomoseres til én enkelt åpning i rørprotesen. Like før denne anastomosen gjøres ferdig, fjerner man perfusjonskatetrene. Slik blir iskemitiden bare et par minutter. Ofte må man anlegge en separat bypass til venstre nyrearterie. Til sist sys distale anastomose til aorta, eventuelt til bekkenarteriene (fig 4). Under operasjonen har man latt pasientens temperatur gå ned til $32-34{ }^{\circ} \mathrm{C}$, mot slutten av operasjonen må oppvarmingen gjøres via den ekstrakorporale sirkulasjonen slik at en temperatur på $36{ }^{\circ} \mathrm{C}$ oppnås. Når eventuelle blødninger er stoppet og pasienten er hemodynamisk stabil, stoppes pumpen og slangene til perfusjonssystemene fjernes.

Enkelte bruker monitorering av ryggmargsfunksjonen under inngrepet. Måling av motoriske aksjonspotensialer forutsetter stimulering med elektriske impulser transkranialt og registrering i underekstremitetenes muskulatur. Disse registreringene kan gi nyttig informasjon om hvilke interkostal- og lumbalarterier som må reimplanteres (5).

\section{Postoperativ behandling \\ og resultater}

Postoperativt er det viktig å holde arterietrykket stabilt og på et nivå omkring $130-150 \mathrm{~mm} \mathrm{Hg}$ systolisk. Det kan være aktuelt å tilstrebe et noe høyere trykk hos pasienter som på forhånd har hatt hypertoni. Postoperativt blodtrykksfall kan være en medvirkende faktor ved iskemiske komplikasjoner fra ryggmargen, med paraplegi eller paraparese som resultat (18). Slike komplikasjoner kan oppstå flere dager etter operasjonen (senparaplegi) og er viktige å erkjenne så raskt som mulig. Senparaplegi, der pasienten altså våkner opp med intakt motorisk funksjon like etter operasjonen, men så får lammelser i det postoperative forløp, kan være reversibel. En forutsetning er at behandling med drenering av cerebrospinalvæske, optimalisering av blodtrykk og normalisering av hemoglobinnivå iverksettes umiddelbart (19-21).

Til tross for betydelige forbedringer i ane- stesiteknikk, monitorering og operativ teknikk er det fortsatt en viss komplikasjonsfrekvens etter disse inngrepene, spesielt etter rekonstruksjon for type II-aneurismer. 30dagersmortaliteten etter elektive operasjoner ligger i dag på $4-15 \%$, avhengig av aneurismets utbredelse og grunntilstanden $(1,5,7)$. Ved ruptur er mortaliteten høyere (16). Lungekomplikasjoner og behov for respiratorbehandling ses hos ca. $15 \%$, forbigående nyresvikt hos en tilsvarende andel pasienter. Risikoen for paraplegi og paraparese er blitt betydelig redusert de siste årene, og en frekvens av nevrologisk sekvele på $2-10 \%$ rapporteres $(5-7)$. Pasienten bør få god informasjon om muligheten for ovennevnte komplikasjoner når det skal tas stilling til selve inngrepet. Hos hver pasient kreves det individuell bedømmelse av hvorvidt operasjon eller konservativ behandling skal anbefales. Operasjonene bør gjøres ved sentre med en samlet ekspertise på området. Det er påvist en sammenheng mellom operasjonsvolum og resultater etter disse operasjonene (22), derfor er det naturlig at de utføres på få steder.

\section{Hybridoperasjoner}

En hybridoperasjon er en kombinasjon av åpen operasjon og endovaskulær behandling. Dette er særlig aktuelt når det er kontraindikasjon mot åpen torakoabdominal kirurgi. Teknikken går ut på å legge ekstraanatomisk bypass til nyrearterier og de viscerale kar (11). Dette gjøres via laparotomi. Torakotomi unngås. Selve den patologiske aorta ekskluderes fra sirkulasjonen med innsetting av et stentgraft via a. femoralis i lysken (fig 5).

\section{Endovaskulær terapi}

Endovaskulær behandling av torakoabdominale aortaaneurismer kan gjøres ved at man plasserer stentgraft i torakal- og abdominalaorta (fig 6). Hvis nødvendig kan man utstyre dette med sidearmer til a. coeliaca, a. mesenterica superior og nyrearteriene. Stentgraftet ekskluderer den aneurismatiske aorta fra sirkulasjonen, og sidearmene sikrer perfusjon av ovennevnte arterier. Ved enkelte type I-aneurismer kan det være tilstrekkelig å sette sidearm i a. coeliaca, eventuelt overstente denne.

Det finnes ulike systemer for stentgraft med sidearmer, og applikasjonen av dem er teknisk krevende (8-10). Det trengs meget god bildekvalitet med tredimensjonal fremstilling av aneurismet og de viktigste sidegrener. På hovedprotesen, som ekskluderer den syke aorta fra sirkulasjonen, har man applisert mindre utløpere der man kan feste stentgraft som passer inn i sidegrenene. Stentgraftet må tilmåles nøyaktig og produksjonen tar tid, noe som gjør at denne operasjonsformen foreløpig ikke egner seg for pasienter som trenger et inngrep raskt, for eksempel ved ruptur. Bedre teknologi vil kanskje medføre at dette kan bli den fore-

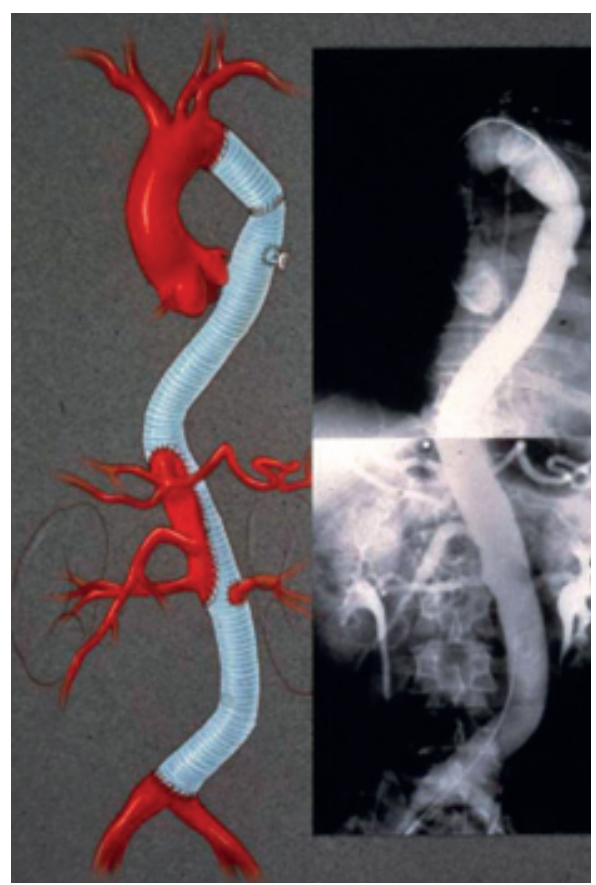

Figur 4 Til venstre: Skjematisk fremstilling av en ferdig utført torakoabdominal aortareseksjon med implantasjon av protese. A. coeliaca, mesenterica superior og høyre nyrearterie er sydd inn i hovedprotesen på en lapp av aortavev. Venstre nyrearterie er sydd inn separat. Til høyre ses postoperativ angiografi av torakal- og abdominalaorta hos samme pasient. Gjengitt med tillatelse fra Hazim J. Safi (13)

trukne behandlingsmetoden i fremtiden, men foreløpig er åpen kirurgi standardbehandling.

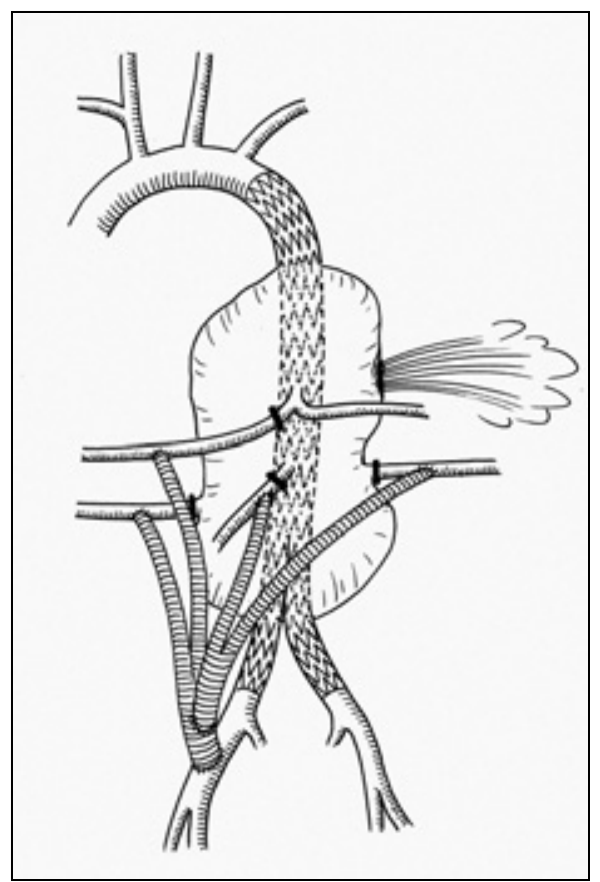

Figur 5 Skjematisk fremstilling av en hybridoperasjon hos en pasient som ble innlagt med rumpert torakoabdominalt aortaaneurisme. Det er anlagt bypass til nyrearteriene og de viscerale kar, og disse er ligert sentralt. Et stentgraft ekskluderer aorta fra sirkulasjonen 


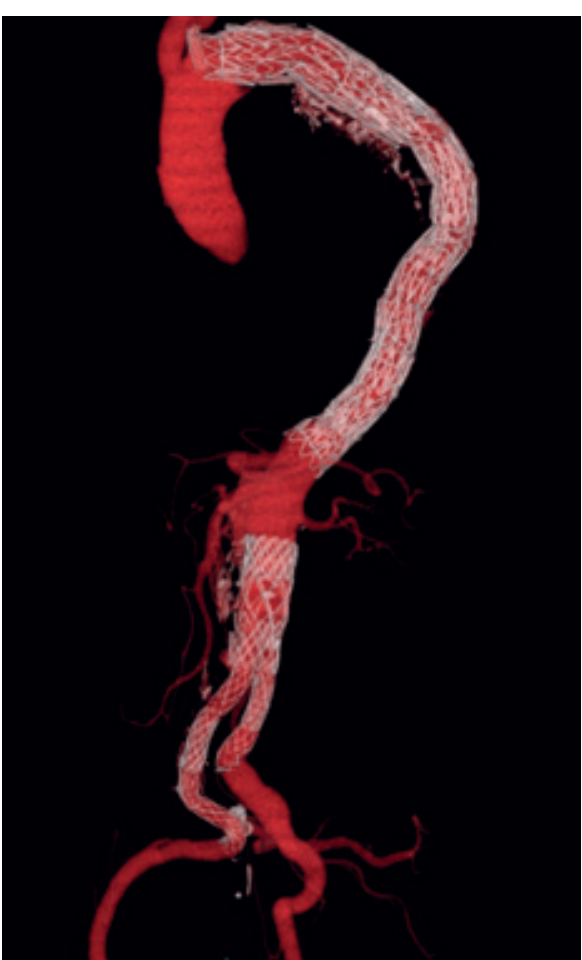

Figur 6 Stentgraftbehandling for et torakoabdominalt aortaaneurisme på basis av type B-aortadisseksjon. Denne pasienten hadde smerter i brystet og en aneurismatisk utvidelse med maksimal diameter på 9,5 cm. Han er i god allmenntilstand 11 år senere

\section{Konklusjon}

Forekomsten av torakoabdominale aortaaneurismer er antakelig økende og behandlingen er stadig blitt bedre. Nøyaktig preoperativ utredning er essensielt. Det er viktig å informere pasienten godt før et eventuelt operativt inngrep. Inngrepene er krevende, ofte må man bruke ekstrakorporal sirkulasjon, og et multidisiplinært samarbeid er nødvendig. Alle terapimuligheter (åpen kirurgi, hybridoperasjoner og stentgraft) må være tilgjengelig når man skal behandle disse pasientene.

Oppgitte interessekonflikter: Ingen

\section{Litteratur}

1. Safi HJ, Miller CC, Huynh TT et al. Distal aortic perfusion and cerebrospinal fluid drainage for thoracoabdominal and descending thoracic aortic repair. Ten years of organ protection. Ann Surg 2003; 238: 371-81.

2. Crawford ES. Thoraco-abdominal and abdominal aortic aneurysms involving renal, superior mesenteric, and celiac arteries. Repair of thoracoabdominal aortic aneurysms with fenestrated and branched endovascular stent grafts. Ann Surg 1974; 179: 763-72.

3. Myhre HO, Christensen O, Levang OW et al. Kirurgisk behandling av torakoabdominale aortaaneurismer. Tidsskr Nor Lægeforen 1987; 6: 531 -4.

4. Svensson LG, Crawford ES, Hess KR et al. Experience with 1509 patients undergoing thoracoabdominal aortic operations. J Vasc Surg 1993; 17 357-70

5. Jacobs MJ, Mommertz G, Koeppel TA et al. Surgical repair of thoracoabdominal aortic aneurysms. J Cardiovasc Surg 2007; 487: 49-58.

6. Coselli JS, Bozinovski J, LeMaire SA. Open surgical repair of 2286 thoracoabdominal aortic aneurysms. Ann Thorac Surg 2007; 83: 5862-4.

7. Safi HJ, Estrera AL, Azizzadeh A et al. Progress and future challenges in thoracoabdominal aortic aneurysm management. World J Surg 2008; 32: $355-60$.

8. Anderson JL, Adam DJ, Berce M et al. Repair of thoracoabdominal aortic aneurysms with fenestrated and branched endovascular stent grafts. J Vasc Surg 2005; 42: 600-7.

9. Chuter TAM, Rapp JH, Hiramoto JS et al. Endovascular treatment of thoracoabdominal aortic aneurysms. J Vasc Surg 2008; 47: 6-16

10. Roselli EE, Greenberg RK, Pfaff $K$ et al. Endovascular treatment of thoracoabdominal aortic aneurysms. J Thorac Cardiovasc Surg 2007; 6 : $1474-82$

11. Lundbom J, Hatlinghus S, Ødegård A et al. Combined open and endovascular treatment of complex aortic disease. Vascular 2004; 12: 93-8.

12. Crawford ES, Crawford JL, Safi HJ et al. Thoracoabdominal aortic aneurysms: preoperative and intraoperative factors determining immediate and long-term results of 605 operations. J Vasc Surg 1986; 3: 389-404

13. Winnerkvist A. Management of thoracoabdominal aortic aneurysms and dissections. With emphasis on spinal cord protection in aneurysm repair and non-surgical treatment of type B dissection. Doktoravhandling. Stockholm: Karolinska University Press, 2006.

14. Crawford ES, DeNatale RW. Thoracoabdominal aortic aneurysm: observations regarding the natural course of the disease. J Vasc Surg 1986; 3: $578-82$.

15. Schwartz LB, Belkin M, Donaldson MC et al. Improvements in results of repair of type IV thoracoabdominal aortic aneurysms. J Vasc Surg 1996; 24: 74-81.

16. Cowan JA, Dimick JB, Wainess RM et al. Ruptured thoracoabdominal aortic aneurysm treatment in the United States: 1988 to 1998. J Vasc Surg 2003, 38: $319-22$

17. Myhre HO, Haaverstad R. Prevention of postoperative paraplegia during thoracoabdominal aortic surgery. I: Sakalihasan N, Kuivaniemi H, Michel JB. Current techniques and results. Aortic aneurysms. New insights into an old problem. Liège: Les Éditions de l'Université de Liège, 2008 280-95.

18. Kawanishi Y, Okada K, Matsumori M et al. Influence of perioperative hemodynamics on spinal cord ischemia in thoracoabdominal aortic repair. Ann Thorac Surg 2007; 84: 488-92.

19. Estrera AL, Miller CC. Huynh TT et al. Preoperative and operative predictors of delayed neurologic deficit following repair of thoracoabdominal aortic aneurysm. J Thorac Cardiovasc Surg 2003; 126: $1288-94$.

20. Aadahl P, Sæther OD, Lundbom J et al. Delayedonset paraplegia after thoracic and thoracoabdominal aortic aneurysm repair: reversal with cerebrospinal fluid drainage. Eur J Vasc Endovasc Surg Extra 2003; 6: 39-42.

21. Svensson LG. Paralysis after aortic surgery: in search of lost cord function. Surgeon 2005; 3: $396-405$

22. Cowan JA, Dimick JB, Henke PK et al. Surgical treatment of intact thoracoabdominal aortic aneurysms in the United States: hospital and surgeon volume-related outcomes. J Vasc Surg 2003; 37: 1169-74.

Manuskriptet ble mottatt 21.1. 2009 og godkjent 3.9. 2009. Medisinsk redaktør Odd Terje Brustugun. 